\title{
CONSTRUCTION, VERIFICATION OF A SOFTWARE FOR THE 2D DAM-BREAK FLOW AND SOME ITS APPLICATIONS
}

\author{
Hoang Van lai, Nguyen Thanh Don \\ Institute of Mechanics
}

\begin{abstract}
In this paper the numerical method for the shallow water equations is studied. The paper consists of 3 sections. In the section 1 the theoretical basis and software IMECH_2DBREAK for simulation of the 2D dam-break or dyke-break flows is outlined. In the section 2 some results in verification of the IMECH_2DBREAK by the test cases proposed in the big European Hydraulics Laboratories are shown. In the last section some applications of IMECH_2DBREAK for the inundation problem in the Red river delta in the Northern of Vietnam are presented.
\end{abstract}

\section{INTRODUCTION}

Analyses of the dam-break or the dyke-break flows play an essential role when considering reservoir and dyke safeties for developing emergency plans. The rapid and continuing development of computing power and techniques during the last years has allowed significant advances in the numerical modelling techniques in that difficult and important problem.

The shallow water equations (SWE) are accepted for many practical applications as properly modelling the unsteady flow of water in general, modelling the dam-break and the dyke-break flows in particular. Many computational methods have been reported successful for SWE. In the last few years a lot of effort has been devoted to the development of the finite volume method (FVM) in modelling the dam-break and the dyke-break flows and many papers have been published (see, for instance, [1] - [6]).

In this paper we concentrate on the Roe technique in FVM for SWE, especially in the case of the flow with shock waves.

The paper is organized as follows. After introduction in the section 1 the main formulas of the FVM for SWE are outlined, the boundary conditions for FVM are described. Applying those formulas and conditions, a software IMECH_2DBREAK for simulation of the 2D dam-break or dyke-break flows has been constructed. In the section 2 the results in verification of IMECH_2DBREAK for the well known test cases are presented. In section 3 some applications of IMECH_2DBREAK software for studying the inundation problem in the Red River Delta are demonstrated.

\section{THEORETICAL BASIS AND SOFTWARE CONSTRUCTION.}

The two-dimensional shallow-water equations: The 2D SWE in a conservative form are written as follows (see |3]):

$$
\frac{\partial U}{\partial t}+\frac{\partial E}{\partial x}+\frac{\partial G}{\partial y}=H
$$


with $H=H^{(1)}+H^{(2)}$,

$$
\begin{aligned}
& U=\left(\begin{array}{l}
h \\
q_{x} \\
q_{y}
\end{array}\right), \quad E=\left(\begin{array}{l}
q_{x} \\
\frac{q_{x}^{2}}{h}+\frac{g h^{2}}{2} \\
\frac{q_{x} q_{y}}{h}
\end{array}\right), G=\left(\begin{array}{l}
q_{y} \\
\frac{q_{x} q_{y}}{h} \\
\frac{q_{y}^{2}}{h}+\frac{g h^{2}}{2}
\end{array}\right), \quad H^{(2)}=\left(\begin{array}{l}
0 \\
F\left(q_{x}\right) \\
F\left(q_{y}\right)
\end{array}\right) \\
& H^{(1)}=\left(\begin{array}{l}
0 \\
g h S_{0, x} \\
g h S_{0, y}
\end{array}\right)
\end{aligned}
$$

where $h, q_{x}, q_{y}$, are unknown functions, $h=h(x, y, t)$ is the flow depth, $q_{x}=q_{x}(x, y, t)$ and $q_{y}=q_{y}(x, y, t)$ are the unit-width discharge components $\left(q_{x}=u h\right.$ and $q_{y}=v h$ with $u, v$ are the depth-averaged velocities) in $x$ and $y$ directions, respectively, $g$ is the gravity acceleration, $S_{0, x}, S_{0, x}$ are the bed slopes

$$
S_{0, x}=-\frac{\partial z_{b}}{\partial x} ; \quad S_{0, y}=-\frac{\partial z_{b}}{\partial y}
$$

$z_{b}$ is bottom elevation and $F\left(q_{x}\right), F\left(q_{y}\right)$ are the bed shear stresses in $x$ and $y$ directions, respectively:

$$
\mathrm{F}(\mathrm{qx})=-\mathrm{F}(\mathrm{qx})=-g q_{x} \frac{\sqrt{u^{2}+v^{2}}}{C_{h, x}^{2}} ; \quad \mathrm{F}(\mathrm{qy})=-g q_{y} \frac{\sqrt{u^{2}+v^{2}}}{C_{h, y}^{2}},
$$

$C_{h, x}=K_{s, x} h^{2 / 3}, C_{h, y}=K_{s, y} h^{2 / 3}$, where $C_{h, x}, C_{h, y}$ and $K_{s, x}, K_{s, y}$ are Chezy and Strickler coefficients.

The Finite Volume Method: Given a computational (for example triangle) mesh (see Fig. 1). This mesh divide the domain into small cells (triangles) $V_{i}, V_{k}, \ldots$ The integrated form of equation (2.1) for a fixed area $V_{i}$ is:

$$
\int_{V_{i}} \frac{\partial U}{\partial t} d V+\int_{V_{i}}\left[\frac{\partial E}{\partial x}+\frac{\partial G}{\partial y}\right] d V=\int_{V_{i}} H d V
$$

The application of the Green theorem to (2.4) for $V_{i}$, yields:

$$
\int_{V_{i}} \frac{\partial U}{\partial t} d V+\oint_{C}(E, G) \cdot \vec{n} d c=\int_{V_{i}} H d V
$$

The contour integral in (2.5) can be approximated as follows:

$$
\oint_{C}(E, G) \cdot \vec{n} d C=\sum_{k}^{3}(E, G)_{k} \vec{n}_{k} d C_{k}
$$

where $k$ represents the index of the edge $k$ of the volume $V_{i}, n_{k}=\left(n_{x}, n_{y}\right)$ is the unit outward normal, $d C_{k}$ is the length of the edge $k$.

The evaluation of the numerical flux for the normal flux $(E, G)_{k} \cdot n_{k}=F_{k+1 / 2}$ in (2.6) used in this paper is based on the Riemann problem defined by the conditions on the left 


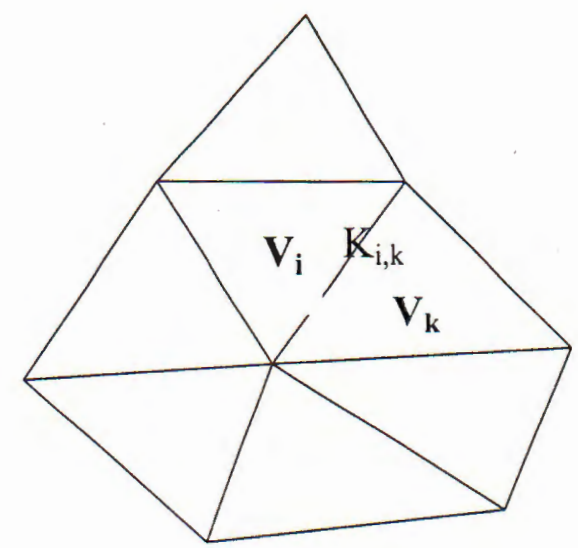

Fig. 1. Unstructured mesh

$\left(U_{L}\right)$ and right $\left(U_{R}\right)$ sides of the edges. For this purpose, the system $(2.1)$ is rewritten in the following form:

$$
\frac{\partial U}{\partial t}+\frac{\partial E}{\partial U} \frac{\partial U}{\partial x}+\frac{\partial G}{\partial U} \frac{\partial U}{\partial y}=H
$$

where

$$
\frac{\partial E}{\partial U}=\left[\begin{array}{lll}
0 & 1 & 0 \\
\left(c^{2}-u^{2}\right) & 2 u & 0 \\
-u v & v & u
\end{array}\right] ; \quad \frac{\partial G}{\partial U}=\left[\begin{array}{lll}
0 & 0 & 1 \\
-u v & v & u \\
\left(c^{2}-v^{2}\right) & 0 & 2 v
\end{array}\right]
$$

The Jacobian matrix $A_{n}$ of the normal flux in (2.7) is evaluated as (see [3]):

$$
A_{n}=\left[\begin{array}{lll}
0 & n_{x} & n_{y} \\
\left(c^{2}-u^{2}\right) n_{x}-u v n_{y} & 2 u n_{x}+v n_{y} & u n_{y} \\
-u v n_{x}+\left(c^{2}-v^{2}\right) n_{y} & v n_{x} & u n_{x}+2 v n_{y}
\end{array}\right]
$$

The eigenvalues of $A_{n}$ are

$$
\begin{aligned}
& \lambda_{1}=\mathrm{unx}+\mathrm{vny}+\mathrm{c} \\
& \lambda_{2}=\mathrm{unx}+\mathrm{vny}, \\
& \lambda_{3}=\mathrm{unx}+\mathrm{v} n \mathrm{n}-\mathrm{c}
\end{aligned}
$$

where $c=\sqrt{g h}$

The eigenvectors of $A_{n}$ are

$$
\vec{r}_{1,3}=\left[\begin{array}{l}
1 \\
u \pm c n_{x} \\
v \pm c n_{y}
\end{array}\right] ; \quad \vec{r}_{2}=\left[\begin{array}{l}
0 \\
-c n_{y} \\
c n_{x}
\end{array}\right]
$$

Main computational formulas: In solving of that Riemann problem, as suggested by Roe (see [7]), instead of $A_{n}$, we consider the matrix $A_{n}$, where $A_{n}$ has the same shape as $A_{n}$ but is evaluated at an average state given by the following quantities $\tilde{u}, \tilde{v}$ and $\tilde{c}$,

$$
\tilde{u}=\frac{\sqrt{h_{R}} u_{R}+\sqrt{h_{L}} u_{L}}{\sqrt{h_{R}}+\sqrt{h_{L}}} ; \quad \tilde{v}=\frac{\sqrt{h_{R}} v_{R}+\sqrt{h_{L}} v_{L}}{\sqrt{h_{R}}+\sqrt{h_{L}}} \quad \text { and } \quad \tilde{c}=\sqrt{\frac{g\left(h_{R}+h_{L}\right)}{2}}
$$

and the normal flux $(E, G)_{k} \cdot n_{k}=F_{k+1 / 2}$ in (2.6) is evaluated as (see [1]):

$$
F_{k+1 / 2}=\frac{1}{2}\left[f\left(U^{L}\right)+f\left(U^{R}\right)-\sum_{k=1}^{n}\left|\lambda_{k}\right|\left(\beta_{k}-\alpha_{k}\right) \vec{r}_{k}\right]
$$




$$
\begin{aligned}
& \beta_{1,3}-\alpha_{1,3}=\frac{h_{k}-h_{L}}{2} \pm \frac{1}{2 \tau}\left[\left(q_{x, R}-q_{x, L}\right) n_{x}+\left(q_{y, R}-q_{y, L}\right) n_{y}-\left(\hat{u} n_{x}+\hat{v} n_{y}\right)\left(h_{R}-h_{L}\right)\right] \\
& \beta_{2}-\alpha_{2}=\frac{1}{\tau}\left[\left(\left(q_{y, R}-q_{y, L}\right) \tilde{v}\left(h_{k}-h_{L}\right)\right) n_{x}-\left(\left(q_{x, R}-q_{x, L}\right)-\tilde{u}\left(h_{k}-h_{L}\right) n_{y}\right]\right.
\end{aligned}
$$

Finally, we get the following computational formula:

$$
\frac{U_{i}^{n+1}-U_{i}^{n}}{\Delta t} V_{i}+\sum_{k=1}^{N}(E, G)_{k} \cdot \vec{n}_{k} \cdot d c_{k}=H_{i}
$$

In the formula (2.9): $U_{i}^{n+1}$ is unknown numerical solution at time $t_{n+1}=t_{n}+\Delta t$, $U_{i}^{n}$ is known numerical solution at time $t_{n},(E, G)_{k} \cdot n_{k}=F_{k+1 / 2}$ are the normal fluxes computed by the formula (2.8), $H_{i}$ is an approximation of the integral $\int_{S i} H d S$ for source terms.

Boundary conditions. For calculation of $U_{i}^{n+1}$ in (2.9) for the volume $V_{i}$ we need the value $U_{i}^{n}$ of the volume $V_{i}$ and the values $U_{k}^{n}$ of all surrounding volumes $V_{k}$. So, we can use (2.9) only for the case when $V_{i}$ is the inside volume.

In the case, when $V_{i}$ is a boundary volume, we do not know the value $U$ for some edge $k$ and we need to use boundary conditions.

It is well known that (see, for example, [3], [4]), depending on both the value of the normal velocity through the boundary $(\mathbf{u} \cdot \mathbf{n})=u n_{x}+v n_{y}$ and the local Froude number $F r=(\mathbf{u} \cdot \mathbf{n}) / c,(c=\operatorname{sqrt}(g h))$, there are four possibilities:

(i) Supercritical inflow: $(\mathbf{u} \cdot \mathbf{n}) \leq-c$ : all the variables must be imposed.

(ii) Subcritical inflow: $-c<(\mathbf{u} \cdot \mathbf{n}) \leq 0$ : two variables must be imposed.

(iii) Supercritical outflow: $(\mathbf{u} \cdot \mathbf{n})>c$ : none of the variables must be imposed.

(iv) Subcritical outflow: $0<(\mathbf{u} \cdot \mathbf{n}) \leq c$ : one variable must be imposed.

Using now these boundary conditions and computational formulas for boundary volumes in [1] we can compute the flux $(E, G)_{k} \cdot n_{k}$ in (2.9) for the boundary volumes.

\section{Software description.}

\section{Software name: IMECH_2DBREAK}

Software purpose: Simulation of 2D complicated water flow (supercritical flow, flow with shock waves, flows on dry beds,...) in the case of the instant of dam or dyke failures.

Software programming language: FORTRAN 90

Software organization: IMECH_2DBREAK consists of a computational program and a data directory SL2D.

The main part of the computational program is the MODULE: MH2D_HMD.FOR, in which the water depth $h$ and the unit-width discharge components $q_{x}, q_{y}$ are computed by the formula (10).

The input data of the IMECH_2DBREAK store in the directory SL2D and consist of 4 FILES:

- FVUNMESH.DAT describes the unstructured mesh for the computational region.

- FVCODATA.TXT defines common use parameters (computational precision, depths for definition of wet/dry front,...)

- INIVHQ.TXT defines the initial values in the volumes.

- FVBOU3.TXT describes the boundary condition in the case of subcritical outflow (the boundary condition of the type (iv)). 
The information for the other boundary conditions gives in the main program. Namely, no any information is needed for the boundary condition of the type (iii). In the case of inflow boundaries the discharge and water level at the boundaries will be given. IMECH_2DBREAK will compute $q_{x}, q_{y}$ for the boundary condition of the type (ii) and all variables for the boundary condition of the type (i).

The output data of the IMECH_2DBREAK also are stored in the directory SL2D. The output data consist of 2 FILES:

- KTRHUV.TXT consists of the values $h, q_{x}, q_{y}$ in the all volumes at the end of the computational time.

- RES01.DAT store the values of the water levels, the velocities, the wet/dry front at the nodes of the mesh in the TECPLOT format. With this FILE it is easy to get different presentations of the computational results

\section{SOFTWARE VERIFICATION}

The developed IMECH_2DBREAK software has been verified by the test cases proposed in the big European Hydraulics Laboratories (see [14]).

\subsection{Case 1: Total dam-break problem (see [12])}

The computational domain is a rectangular basin of $16 \mathrm{~m} \times 0.1 \mathrm{~m}$. Initially, the free surface elevation presents a discontinuity at abscissa $x=0 . \mathrm{m}$, where a dam is located. The left side of the basin is covered with water at rest, the water depth being $6 \mathrm{~m}$, whereas the right side is dry (Fig. 2). At the start of the simulation the dam is totally and instantly broken and the dam location becomes a critical flow section where the velocity and the depth are constant in time (see [13]). The flow is subcritical to the left of the dam location (upstream part), and supercritical to the right (downstream part).

Fig. 4 and 5 present some results of the IMECH_2DBREAK.

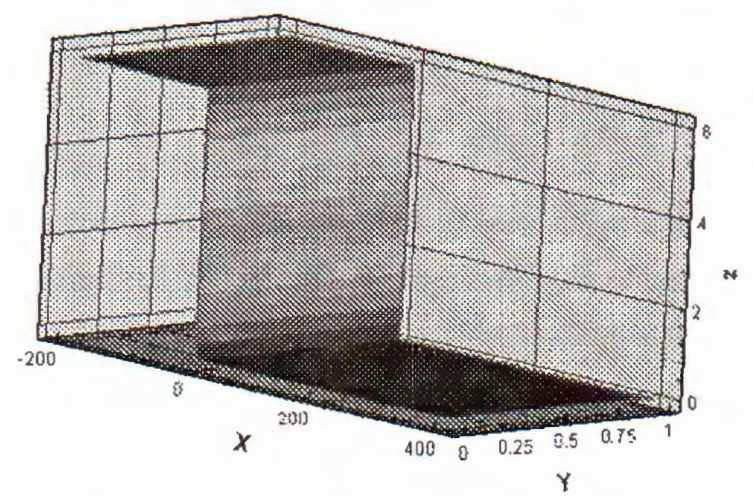

Fig. 2. (Case 1) Water surface at the start of the simulation

\subsection{Case 2: Partial dam-break problem (see [2]):}

The geometry of the problem consists of a $200 \times 200 \mathrm{~m}^{2}$ basin with a non-symmetrical breach. The initial water level of the dam is $10 \mathrm{~m}$ and the tail water is $5 \mathrm{~m}$ high (Fig. 6). At the instant of dam failure, water is released into the downstream side through a breach $75 \mathrm{~m}$ wide. Fig. 8 presents the computed water surface at $7.3 \mathrm{sec}$. Fig. 9 shows the water surface obtained in [2] at the same time. 

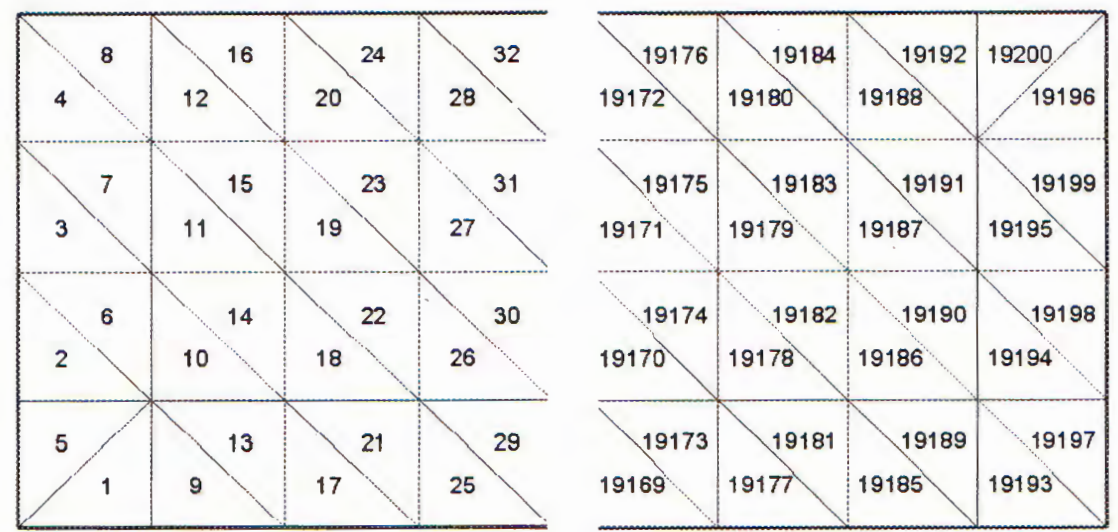

Fig. 3. Computational mesh

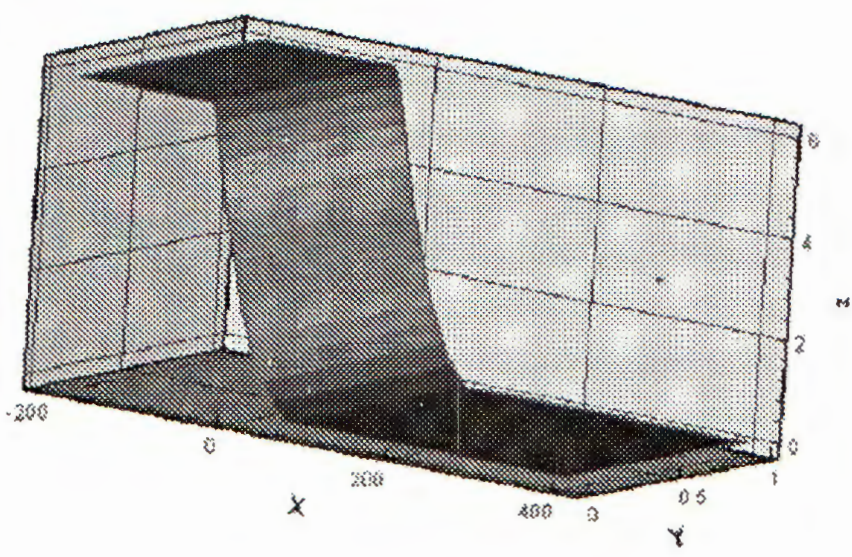

Fig. 4. Water surface at 5 sec. after dam-break

\subsection{Case 3: Dam-break in a channel with a local construction (see [14])}

The channel configuration is presented in Fig. 10. The entire channel, with a zero longitudinal slope, is $19.30 \mathrm{~m}$ long and his rectangular section is $0.50 \mathrm{~m}$ wide. Dam removal time is approximately $0.2 \mathrm{~s}$. The gate is located at a section $6.10 \mathrm{~m}$ from the upstream section of the channel. The variation of the water-depth with time were obtained with four capacitance probes. Fig. 11 presents the measured and computed water levels in the prober N2

\subsection{Case 4: Dam-break in a channel with a non symmetrical flood plain (see [14])}

The entire channel, with a zero longitudinal slope, is $19.30 \mathrm{~m}$ long and his rectangular section is $0.50 \mathrm{~m}$

wide. Dam removal time is approximately $0.2 \mathrm{~s}$. The gate is located at a section 6.10 $\mathrm{m}$ from the upstream section of the channel. The upstream channel is also $0.50 \mathrm{~m}$ wide. The sudden enlargement for the "flood plain" is located $6.45 \mathrm{~m}$ downstream of the gate. 


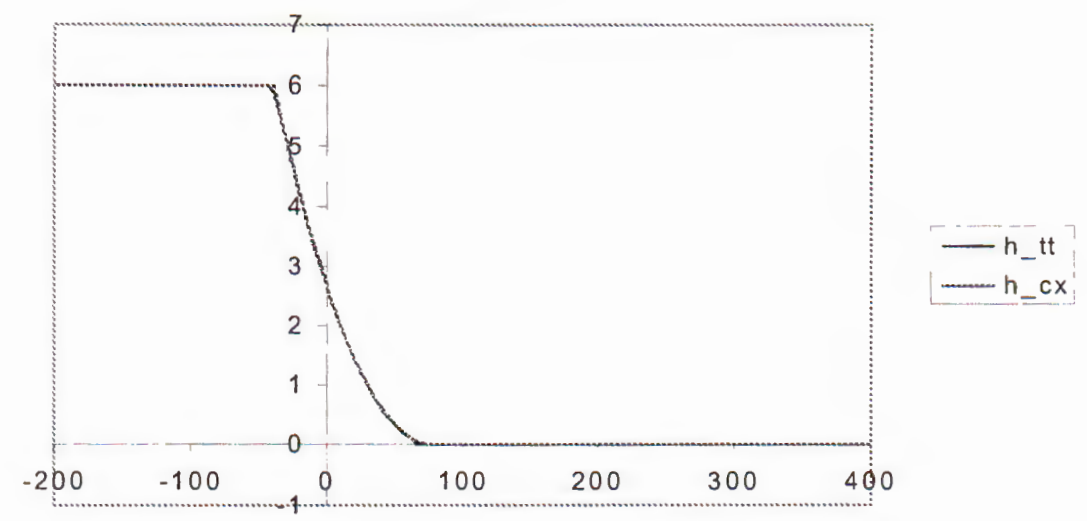

Fig. 5. Exact and computational water levels

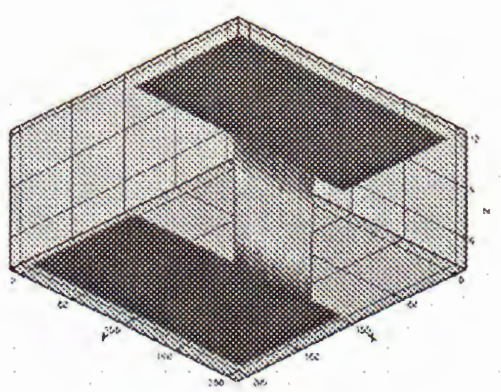

Fig. 6. (Case 2) Water surface at the start of the simulation

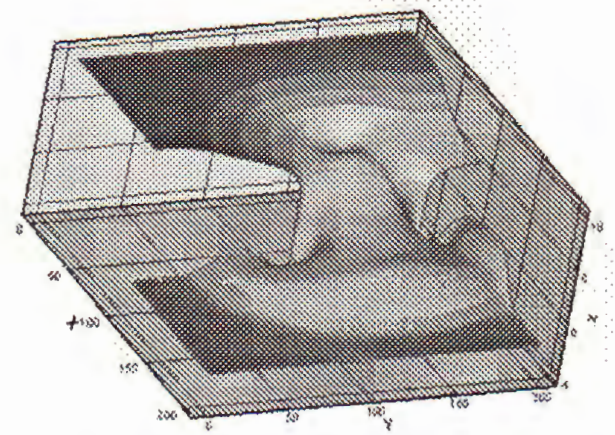

Fig. 8. Water surface at $7.3 \mathrm{sec}$. after dambreak (computed by IMECH_2DBREAK)

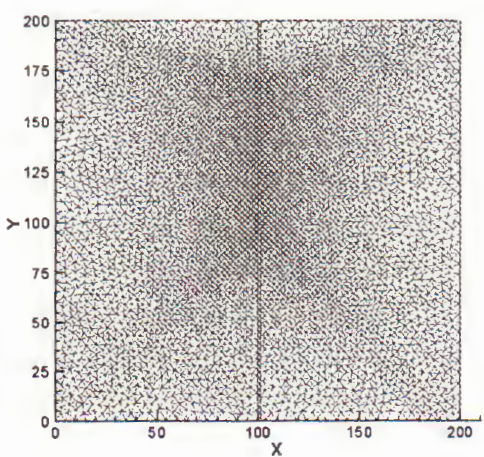

Fig. \%. Computational mesh 


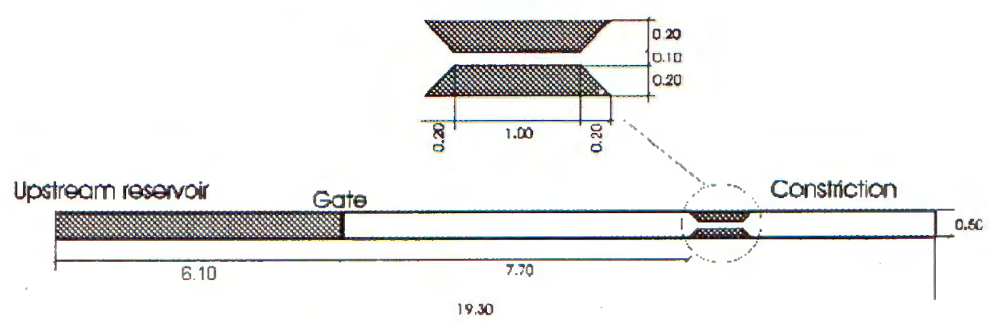

Fig. 10. Channel configuration

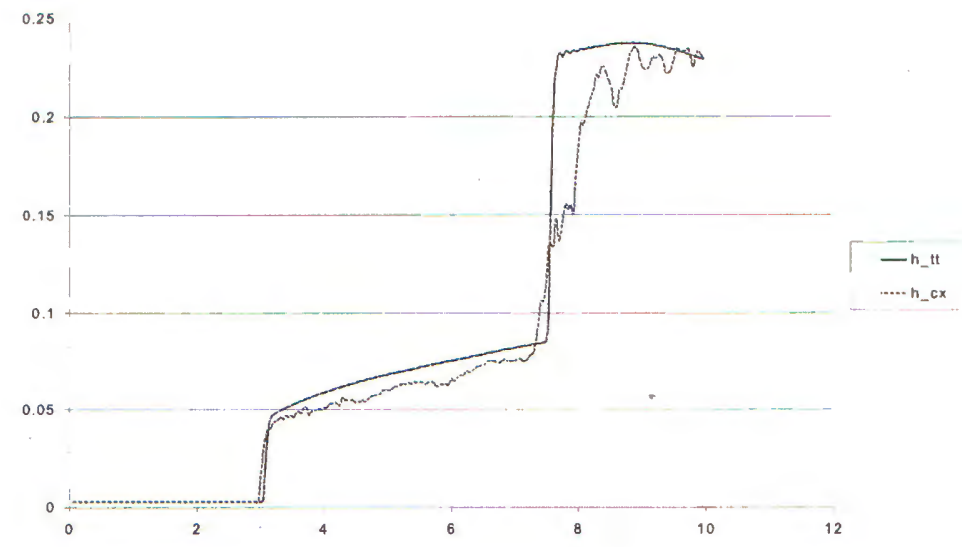

Fig. 11. The measured and computed water levels in the prober N2

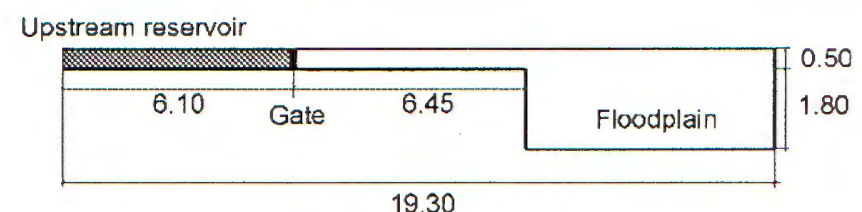

Fig. 12. Channel with floodplain

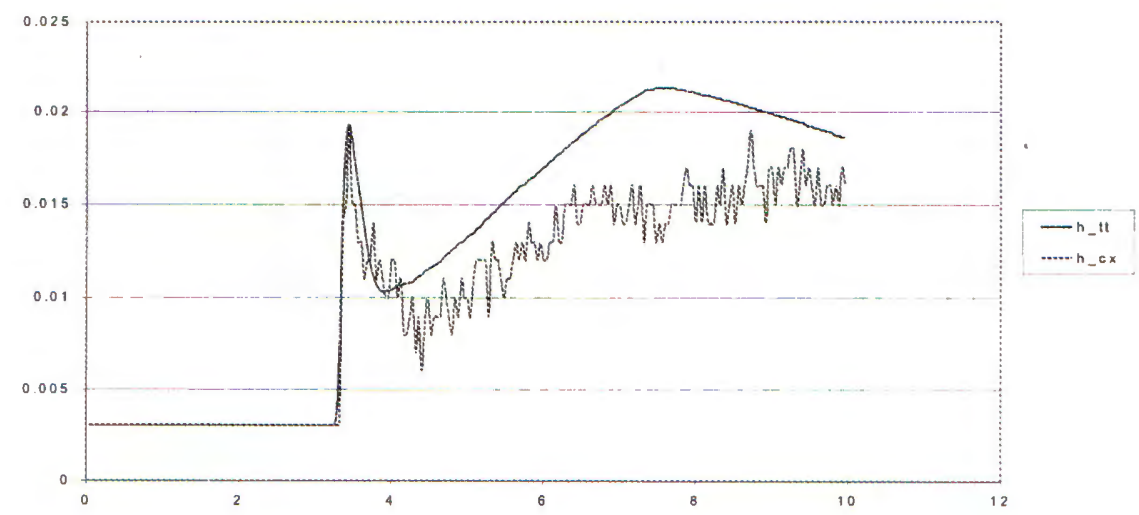

Fig. 13. The measured and computed water levels in the prober N2 


\section{SOFTWARE APPLICATION}

\subsection{Simulation of dyke break flows in Thanh-Ha region}

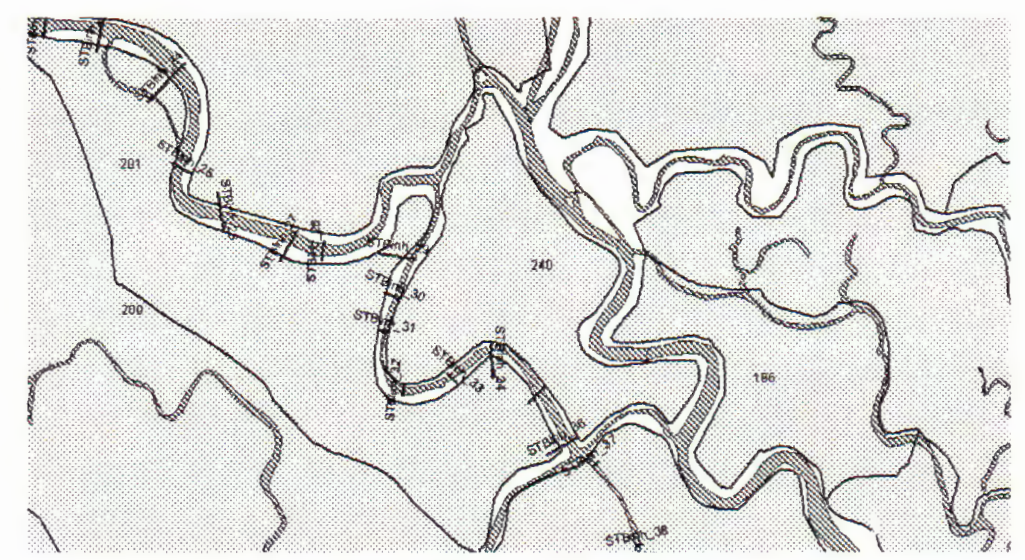

Fig. 14. The Thanh Ha region

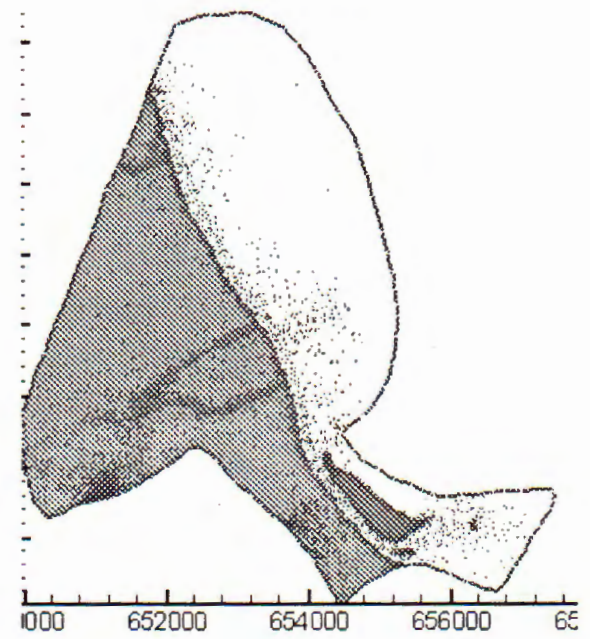

Fig. 15. Inundation in Thanh Ha region at 10 hours after the dyke breach

The geometry of the problem consists of a cell N240 in the Thai Binh river basin (Fig. 14). The area of that region is about 3100 ha. The region is relatively flat (the elevation of the land: $0.9-1.2 \mathrm{~m}$ ), except some roads (the elevation of roads: $1.5-1.8 \mathrm{~m}$.).

In the 1996 year flood 2 places (near the cross-sections STBINH_32 and STBINH_34) of the Thai Binh river dyke were broken. Fig. 15. presents the computational result of the inundation at 10 hours after the dyke breach. This result is agreed with the real inundation process in this region in the 1996 year flood.

\subsection{Simulation of flow caused by an operation of the emergency spillway in Dong-Anh region}

For the flood control in the Red and Thai Binh river system some emergency spillways are studied. One of them is the emergency spillway in Dong Anh region. This region 
consists of 3 cells (N136, N137 and N154) in the Red river basin (Fig. 16). When extreme

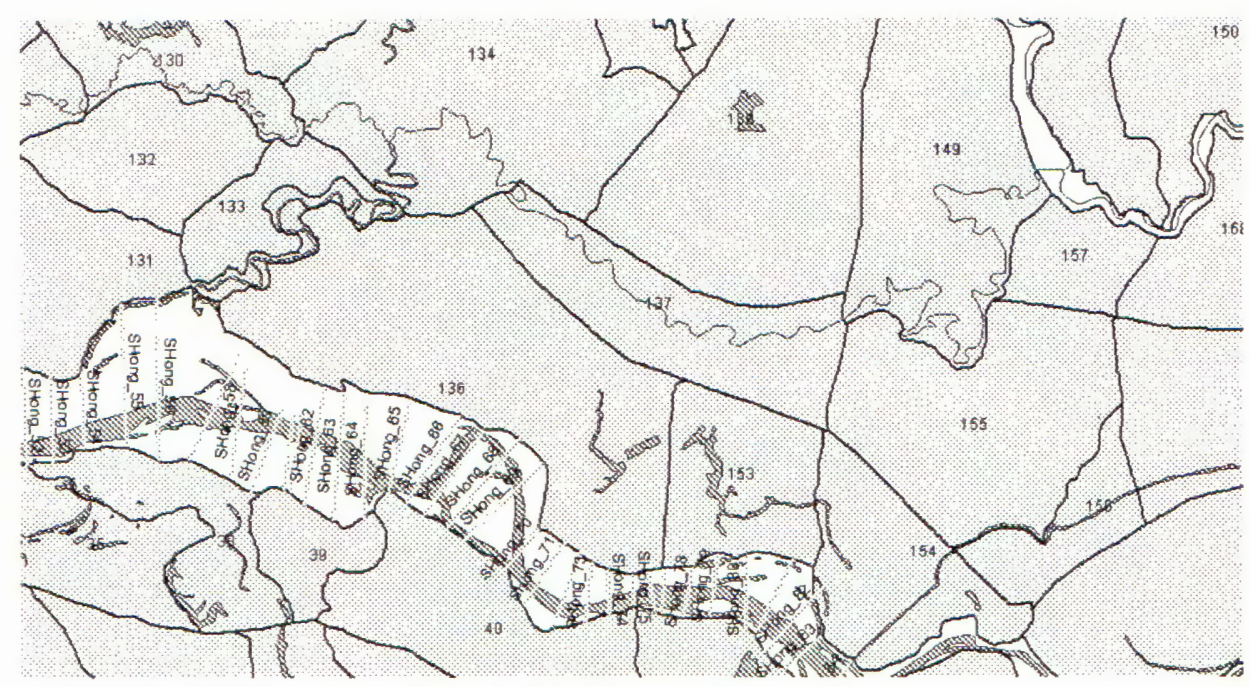

Fig. 16. The Dong Anh region

floods occur, emergency spillways should be operated to avoid passive responses to dyke breakings and severe disasters. It means that the dyke elevation in spillway places will be suddenly decreased and flood water in the river system will overflow temporary dykes in riverbanks. So, operating emergency spillways in the extreme flood will accept certain damage levels but avoiding catastrophe.

The software IMECH_2DBREAK can be used in simulation of an operation of the emergency spillway. Fig. 17. presents the computational result of the inundation at 5 hours after the operation of the emergency spillway in Dong Anh region.

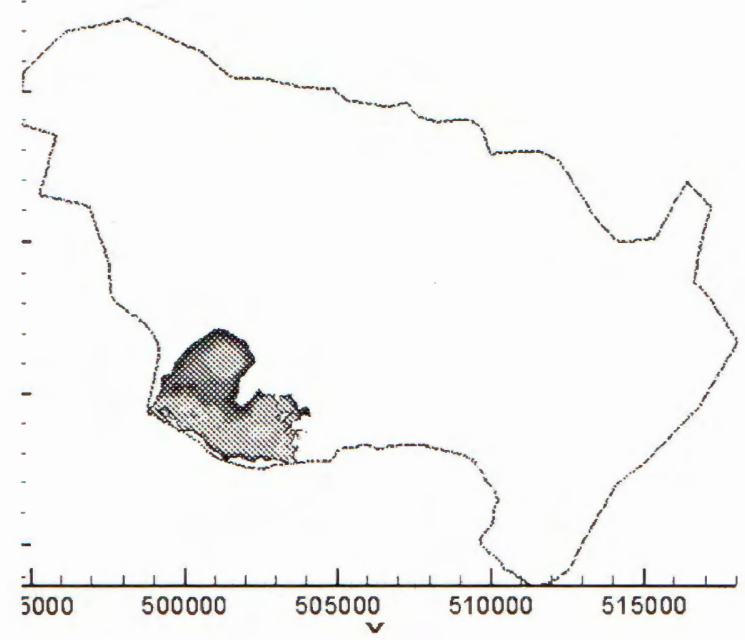

Fig. 17. Inundation in Dong Anh region at 5 hours after the operation of the emergency spillway 


\section{CONCLUSION}

The results in the verification and in the application of IMECH_2DBREAK show that the software is ready for simulations of the dam-break or the dyke-break flows in the cases when the regions are relatively flat.

In the cases of varying bottom the simulations of the dam-break or the dyke-break flows are difficult problems and we shall study those problems in the future.

Acknowledgments. The authors express their gratitude to the National Foundation for Natural science (MOST) for the financial supports to prepare this paper.

\section{REFERENCES}

1. P. A. Sleigh, P. H. Gaskell, M. Berzins and N. G. Wright, An unstructured Finite Volume Algorithm for predicting Flow in Rivers and Estuaries, Computers 63 Fluids 27 (1998) 479-508.

2. K. Anastasiou and C. T. Chan, Solution of the 2D Shallow Water Equations using the Finite Volume Method on Unstructured Triangular Meshes, Int. J. for Num. Meth. in Fluids 24 (1997) 1225-1245.

3. P. Brufau, M. E. Vazquez-Cendom and Garcia-Navarro, A Numerical Model for Flooding and Drying of Irregular Domains, Int. J. for Num. Meth. in Fluids 39 (2002) 247-275.

4. Tran Gia Lich, Le Kim Luan, Boundary Conditions for the Two-dimensionnal Saint-Venant equation system, J. Appl. Math, Modelling 16 (1992) 498-502.

5. S. Guillou and K. D. Nguyen, An improved technique for solving two-dimensional shallowwater problems, Int. J. for Num. Meth. in Fluids 29 (1999) 465-483.

6. Dan Nguyen, Dartus D., Diep Nguyen Van, New Development of Overland, 1-D and 2-D Hydraulic Models for Flood Control in the Red River Delta, Journal of Advances in Natural Sciences 5 (2004).

7. P. L. Roe, Approximate Riemann Solvers, Parameter Vectors, and Difference Schemes, J. Comput. Physics 43 (1981) 357-372.

8. A. Bermudez and M. E. Vazquez, Upwind Methods for Hyperbolic Conservation Laws with Source Terms, Comput. Fluids 23 (1994) 1049-1071.

9. N. Goutal and F. Maurel, Proceedings of the 2 Workshop on Dam-Break Wave Simulation, Technical report HE-43/97/016/A, Electricite de France, Departement Laboratoire National d'Hydraulique Fluviale, 1997.

10. R. J. Fennema and M. H. Chaudhry, Explicit Methods for 2D Transient Free-surface Flows, J. Hydraul. Eng. ASCE 116 (1990) 1013-1034.

11. F. Alcrudo and P.Garcia-Navarro, A High-resolution Godunov-type Schem in Finite Volumes for the 2D Shallow -water Equations, Int. J. for Num. Meth. in Fluids 16 (1993) 489-505.

12. TELEMAC - 2D Version 5.0, Validation Document, July, 2000.

13. A. Ritter, Die Fortpflanzung der wasserwellen, Z. Verdeut. Ing 36, 1892

14. Concerted Action on Dam-Break Modelling (CADAM), www.hrwallingford.co.uk/projects/CADAM. 


\section{XÂY DỰNG, KIỂM DỊNH PHẦN MỀM CHO DÒNG VÕ DẬP 2 CHIỀU VÀ MộT SỐ ÁP DỤNG}

Bài báo này nghiên cứu việc áp dụng phương pháp thể tích hữu hạn trong giải số hệ phương trình nước nông 2 triệu. Bài báo gồm 3 phần. Phần 1 mô tá tóm tắt cơ sở lý thuyết về kỹ thuật của Roe cho phương pháp thể tích hữu hạn trong phần mềm vỡ đập 2 chiều IMECH_2DBREAK. Phần 2 giới thiệu kết quả kiểm định IMECH_2DBREAK qua một số bài toám mẫu do các phòng thưy lực lớn của châu Âu đề xuất. Phần 3 trình bày một số kết quả áp dụng IMECH_2DBREAK để mô phỏng ngập lụt trên đồng bằng sông Hồng sông Thái Bình khi xáy ra sự cố vỡ đê. 